thought of as a reliable characteristic of malignancy but that the added attribute of xenoplasia (ability to grow in a foreign environment) should be taken into consideration. He illustrated this concept by showing several instances in which tumour growth had resulted in the rupture of basement membranes in host tissue but that cells broken off from the tumour mass appeared unable to survive in the newly invaded environment.

Professor J. R. Hobbs (Westminster Hospital, London) in a lucid and well illustrated talk discussed observations that have been made on paraprotein levels in mice and men with immunocytomas. Professor Hobbs said that the term immunocytoma had been adopted to cover abnormal growth of cells which produced immunoglobulins, irrespective of their morphology. He adduced the evidence that paraproteins are produced from clones of cells all secreting recognizably the same product. He failed seriously to bear in mind that informational transfer between cells could give rise to cells which all secrete the same immunoglobulin. At present, however, such notions are suspect and Hobbs's opinion about the monoclonal nature of paraproteins is widely shared. Professor Hobbs established that in mice and men the amount of paraprotein detectable in the serum could be used as an index of tumour growth. He then went on to examine the concept of progression in relation to immunocytomas.

Three kinds of untreated condition are broadly distinguishable. Those in which the paraprotein level though abnormally high was stable, those in which an exponential increase with time was inexorable and those very rare cases in which a previously stable situation progressed to an increasingly abnormal one. Professor Hobbs, however, went on to show that in 45 per cent of all treated cases the condition before treatment and that afterwards could be qualitatively different in a variety of ways. The change, he felt, might well be attributable to the mutagenic effects of the treatment, particularly in those instances in which the new paraprotein showed only a single amino-acid change from the previous one.

\section{anMaL Co.0Barton Jumping for life}

from a Correspondent

THE phenomena of "warning" (aposematic) and "mimetic" (pseudaposematic) colouring in animals have been dealt with in the classic work of $\mathbf{H}$. B. Cott (Adaptive Colouration in Animals, Methuen, 1940) and more recently by E. Wickler (Mimicry in Plants and Animals, Weidenfeld and Nicolson, 1968). Animals which are poisonous, distasteful or otherwise inedible are apt to have conspicuous and characteristic colour patterns, usually in black and yellow or black and red, which may be mimicked by other, more "edible" species.

In a recent article (Entomol. Scand., 2, 41 ; 1971), C. H. Lindroth suggests that patterns of the "warning" type may be borne by species whose only defence is the power of jumping in response to a visual or tactile stimulus. Birds, he suggests, may learn to recognize and to avoid species which habitually frustrate them by jumping just before they can be seized. The examples he considers are drawn from a well known group of jumping insects, the "flea-beetles" (Chrysomelidae-Alticinae). Some species of this group, for example, the South African Diamphidia and Polyclada species used for making arrow poisons, are definitely poisonous and have typical "warning" colours; these species hardly jump at all. In other genera, for example, the American Disonycha, species showing similar types of colouring are strong and ready jumpers and Lindroth quotes evidence that they are not distasteful or poisonous to birds.

Lindroth suggests that these Disonycha species have served as models for mimics; the ones he cites are carabid beetles of the genus Lebia, whose larvae are known or believed to develop parasitically on the pupae of the very same Alticinae which the adults mimic. The adult Lebia are apt to occur on the foodplants with their Disonycha hosts, in relatively small proportions--so the prime requirement for successful Batesian mimicry, that the mimics should be less common than their models, is likely to be fulfilled.

If Lindroth is right about the significance of the colouring of these flea-beetles, it is likely that similar phenomena will be displayed in other jumping animals. Among vertebrates, the most likely group to show them is Anura. The agile African tree-frogs of the genus Hyperolius are diurnally active and liable to show aposematictype patterns (for example, $H$. marmoratus figured by Cott). Among British insects, Alticinae are probably rather too small to make effective use of warning patterns (there are few cases of animals less than about $4 \mathrm{~mm}$ long with colouring which is definitely aposematic), but at least one species of the homopteran bugs, the cercopid Triecphora vulneraia, is of comparable size with the Disonycha species, a strong jumper, and is strikingly marked in bright red and greenish black. It would be interesting to make a particular study of this species with Lindroth's theory in mind.

\title{
Latent Herpes Simplex Infection
}

ONE of the most fascinating aspects of the biology of the herpes viruses, and of herpes simplex virus in particular, is their capacity to persist in their natural hosts in the face of circulating antibodies and periodically to erupt. Many people infected with herpes simplex, for example, periodically and often predictably suffer from recurrent herpetic infections in response to physical or emotional stimuli and the resulting lesions always appear in the same part of the body. Clearly, this virus must persist in infected individuals, but which cells harbour the virus between eruptions? Much indirect evidence has been accumulated which incriminates the sensory ganglia and cells associated with nerve trunks as the reservoirs of the virus; the experiments with rabbits reported in next Wednesday's Nature New Biology (February 16) by Stevens, Nesburn and Cook are more than consonant with that idea.

Stevens and his colleagues find that trigeminal ganglia taken from rabbits a few days after the animals have been infected by dropping suspensions of herpes simplex virus onto the cornea of the eye contain from 70 to 7,200 plaque forming units of the virus per gram of tissue. Clearly, after infecting the eye the virus somehow reaches and infects the trigeminal ganglia. Stevens et al. therefore maintained rabbits with recurrent ocular herpetic infection for 4 to 8 months, daily assaying the tear film for herpes simplex virus. As expected the virus intermittently appeared and disappeared from the tear film; virus could not, however, be detected in, or recovered from, trigeminal ganglia taken from such rabbits. But when portions of trigeminal ganglia were put into organ culture herpes simplex virus could eventually be recovered from at least some of the cultures.

It seems therefore that the virus can latently infect the trigeminal ganglia and can be induced to replicate to yield detectable amounts of virus when the latently infected cells are cultured in vitro. Precisely how the viral genome persists in the latently infected cells remains to be discovered; it may replicate to yield very small amounts of virus which are undetectable with current assay procedures or the viral genome may persist in a repressed state. But, that apart, if herpes simplex virus can latently infect sensory ganglia of rabbits the same may very well be true of man; in other words, sensory ganglia are probably the site of the reservoir of herpes simplex virus in persistent infections of man. 